\title{
Oculcutaneous Disease, Rosacea: Review Article
}

\author{
Amal 0 Al-Balbeesi* \\ Assistant Professor, Department of Dermatology, King Khalid University Hospital, King Saud University, Saudi Arabia
}

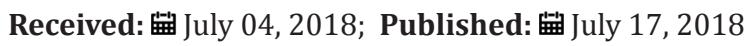

*Corresponding author: Amal O Al-Balbeesi, Assistant Professor, Department of Dermatology, King Khalid University Hospital, King Saud University, Saudi Arabia

\begin{abstract}
Ocular manifestations of rosacea are commonly nonspecific and variable. The etiology of the inflammation is not fully known and there is no definite diagnostic test for the disease. We often under diagnose the disease, despite the potential for serious sightthreatening sequelae. When evaluating patients with rosacea, dermatologists and family physicians should obtain a careful history of eye complaints and examine the eyelid margins thoroughly. Patients with moderate-to-severe ocular findings will benefit from evaluation by an ophthalmologist. Controlling symptoms and preventing potential risk of blindness should be the aim of early diagnosis and prompt intervention. The mainstay of treatment is good lid hygiene, topical metronidazole, topical azithromycin eye drops, topical cyclosporine, and oral tetracycline.
\end{abstract}

The aim of this review is to shed light on the signs of ocular rosacea, dermatologists and family physicians must be familiar with, the understanding of the pathogenesis of this old disease of skin and the eye since the original observation by Von Arlt in 1864 and its treatment.

\section{Quality of Evidence}

A Pubmed search of English-language literature from August 1931 to April 2018 revealed a combination of prospective cohort studies and descriptive studies, with a predominance of descriptive studies based on clinical experience. The MeSH terms; eye, skin, rosacea was used, as well as the non-MeSH terms ocular and oculocutaneous. The articles selected for assessment were the ones that provided complete clinical reviews of relevance, i.e., they provided a thorough review of the cliniาcal presentation of ocular rosacea, its pathophysiology, diagnosis and treatment options.

\section{Introduction}

In dermatology, oculocutaneous diseases such as seen in bullous diseases, atopic dermatitis, and rosacea are often encountered. Many eye structures and the epidermis share the same ectodermal origin that can partially explain the association. Since the original observations of Von Arlt in 1864, we know that the eyes are likely to be involved in rosacea. Von Arlt reported cases of this disease associated with conjunctivitis and shallow, round ulcers of the cornea. He recognized that treatment of the skin condition improved the state of the eye [1].

Ocular involvement with rosacea is an under-appreciated and under diagnosed [2-5]. In patients with ocular and cutaneous rosacea, approximately $53 \%$ have the cutane $\urcorner$ ous eruption first, $20 \%$ with eye findings first and $27 \%$ both simultaneously at onset. Peak incidence for ocu $\neg$ lar rosacea is later than for cutaneous rosacea, commonly occurring in sixth and seventh decades. While cutaneous rosacea affects women twice as often as men, ocular rosacea manifests no sex predilection [6,7]. A strong correlation exists between the degree of ocular involvement and the tendency to flush [8].

Ocular findings can be considered as either minor or major; however, minor findings are more common [4]. Ophthalmic findings are nonspecific on their own and are inde $\neg$ pendent of the severity of the skin disease $[6,9,10]$. Initial ocular complaints consist of sensation of a foreign body, tearing, pain, photophobia, pruritus, stinging, burning, and blurred vision [9,10-13].

Meibomian gland dysfunction occurs in about $50 \%$ to $93 \%$ of rosacea patients, which is the hallmark of the disorder [13,14]. Other ocular manifestations include chronic staphylococcal blepharitis, 
telangiectasia of the lid margin, recurrent chalazae, chronic conjunctivitis, dry eye, peripheral corneal neovascularization, marginal corneal infiltrates with or without ulceration and episcleritis $[15,16]$. The most common ocular findings in adults are hyperemia of the conjunctiva and corneal neovascularization [15]. However, in children the most common ocular findings are meibomian gland disease, recurrent chalazae and conjunctivitis [16]. Dermatologists and primary care physicians must be aware of the signs and symptoms of the major complications of rosacea and know when to refer patients for ophthalmological evaluation and care. Corneal neovascularization, erosion, ulceration and perforation are major complications of rosacea and are better dealt by ophthalmologists. This review covers the pathophysiology, the major and minor clinical manifestations, the diagnosis and therapy of ocular rosacea.

\section{Pathophysiology: Figure 1}

\section{Meibomian Gland Disease}

Meibomian glands (MGs) are rows of enlarged sebaceous glands running along the lid margin posterior to the eyelashes. They produce lipid secretions that retard tear evaporation and are essential for the maintenance of the structural and refractive integrity of the ocular surface. MGD is common in fair-skinned individuals in association with rosacea and old age (Figure 2).

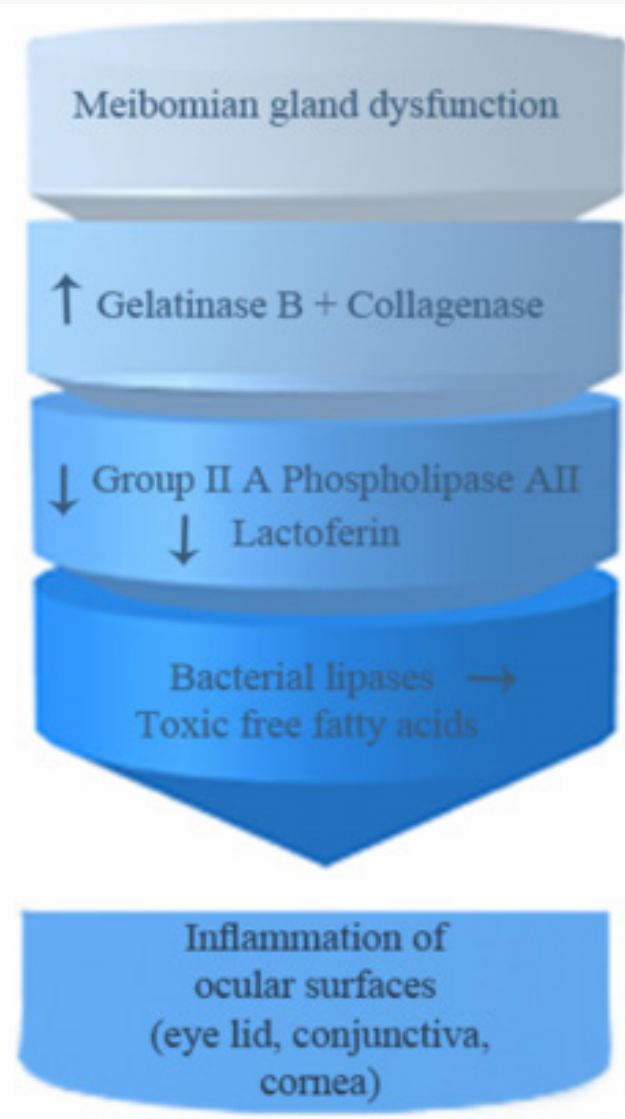

Figure 1: Pathophysiology of ocular rosacea.

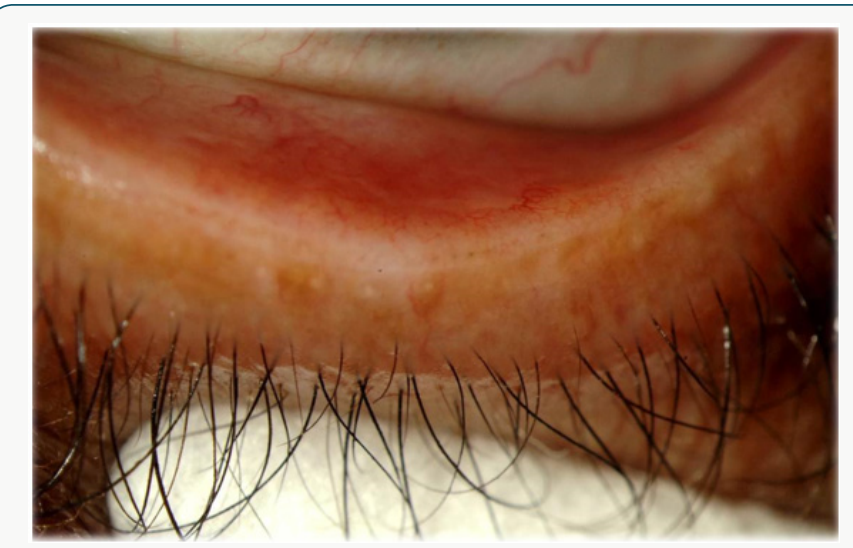

Figure 2: MGD with obliteration of some meibomian glands orifices.

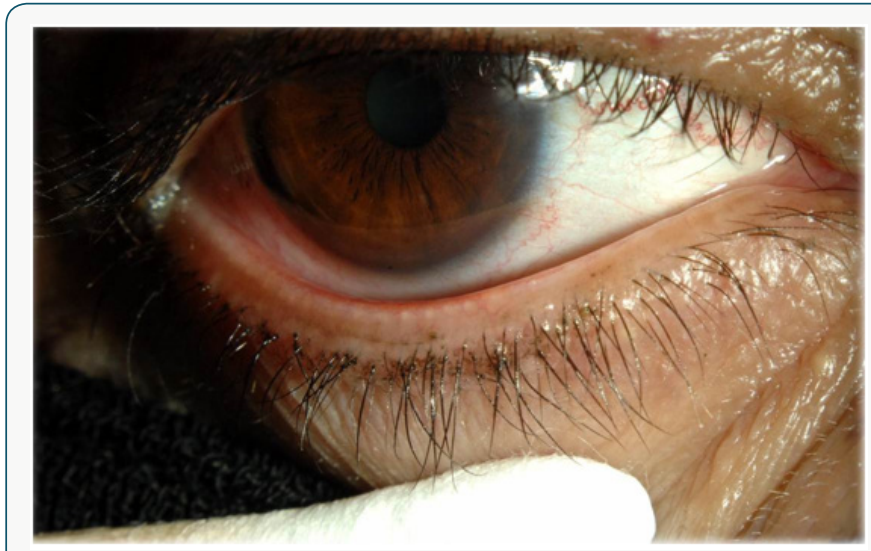

Figure 3: Showing stagnant sebum at meibomian orifices of lower lid.

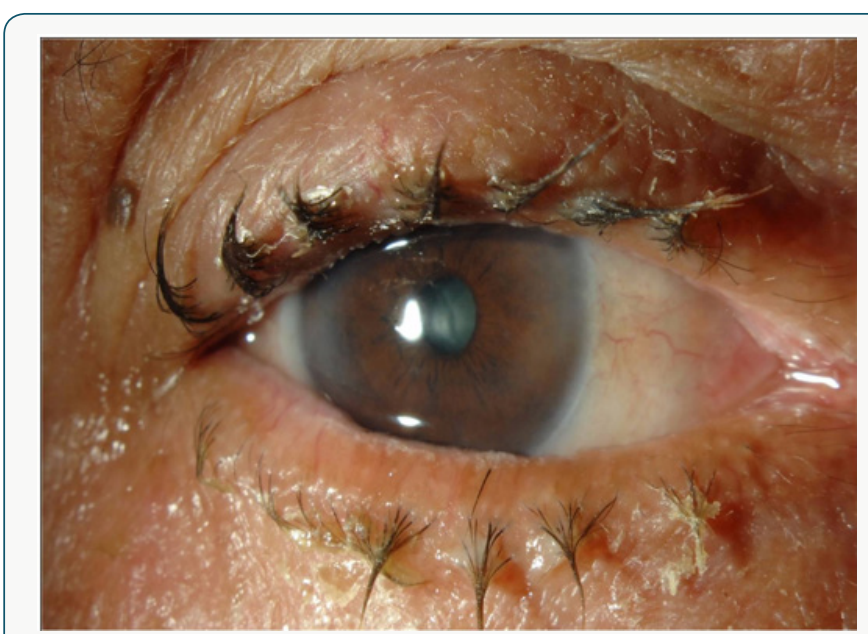

Figure 4: Blepharitis, erythema, edema, discharge and crusting.

MGD (Figures 3 \& 4) is a common cause of blepharitis, meibomian keratoconjunctivitis, keratoconjunctivitis sicca and chalazae that occurs in (100\%, 60\%, 37\% and 57\% respectively) in patients with rosacea [17-22]. In addition to MGD, 5-10\% of patients with ocular 
rosacea develop vascular telangiectasia $[19,23]$ and irregularity of their lid margins and conjunctiva hyperemia [13,23-25] (Figures 5 \& 6). There is a generalized sebaceous gland dysfunction that involves the MGs in rosacea patients [18]. Alterations in lipid secretions (meibum) and abnormal keratinization of the MGs duct orifices have a profound effect on the quality of tear film and on the ocular surface [21]. Sebum excretion rate is not elevated in ocular rosacea [22].

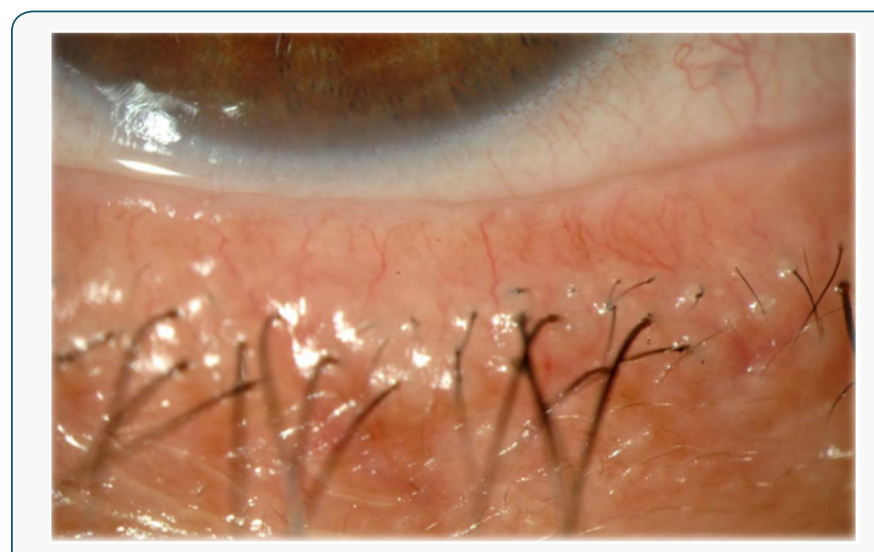

Figure 5: Showing telengiectasia of lid margin.

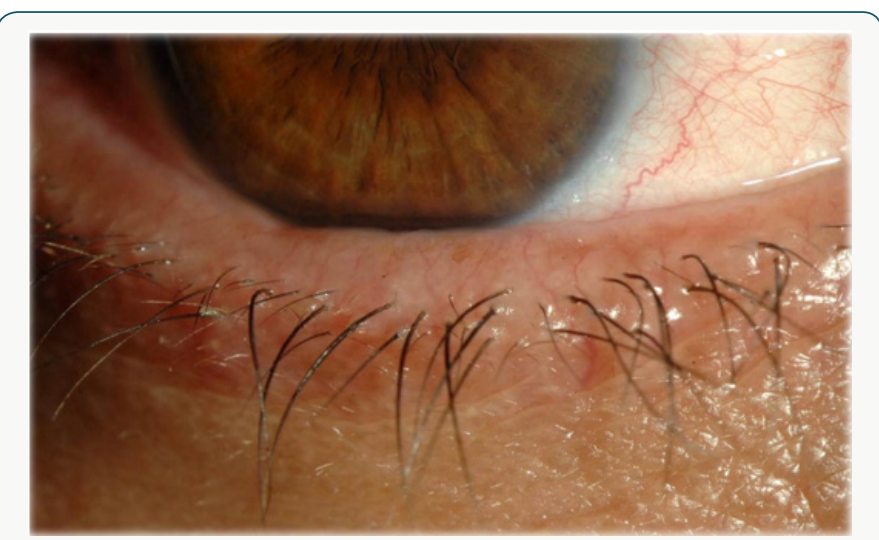

Figure 6: Showing irregularity of internal lid margin.

\section{Gelatinase B}

Gelatinase B, which is a member of the family of matrix metalloprotienase (MMP), is secreted in high levels by the epithelium and stromal keratinocytes of the cornea in response to elevated levels of interleukin-1 alpha (IL-1). Clearance of interleukin-1 alpha (IL-1) in the tear fluid of patients with ocular rosacea is disrupted, that leads to higher than normal levels of the cytokine [26]. MMP and collagenase degrade extracellular matrix and lead to recurrent epithelial erosions, vascularization and epithelial basement membrane dystrophy of the cornea that eventually leads to blindness $[19,23,24,27,28]$. These corneal changes respond to 4 weeks therapy with tetracyclines through reduction of the activity of MMP [29]. Gelatinase B has been implicated as causative factor in sterile corneal ulceration, which makes it a possible therapeutic target to prevent sight threatening complication associated with ocular rosacea [28].

\section{Aqueous Tear Secretion}

The amount of aqueous tear secretion by Schirmer's test for dry eyes is markedly reduced in patients with rosacea [30] (Figure 7). Less than $5-10 \mathrm{~mm}$ of wetting of the inserted Whatman filter paper is suggestive of dry eyes. The paper is inserted in the middle and outer third of the lower eyelid with or without topical anesthesia, after 5 minutes of eye opening and blinking as necessary, the wetting is measured [16].

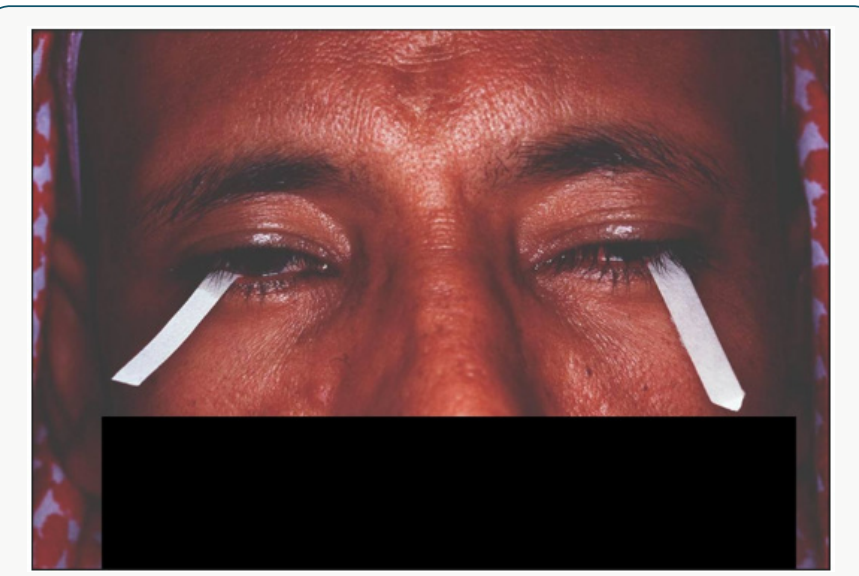

Figure 7: Schermir test for dry eye.

The tear breaks up time TBT, that measures the stability of the tear film, is abnormal in patients of rosacea; dry spots appear in less than 10 seconds on the cornea. The test is done by installing fluorescein dye into the lower eye fornix, patient is asked to blink and stop. By the use of colored light, the time interval between the last blink and dry spot appearance on the cornea is noted by stopwatch. Dry spots appear as black lines or spots [30]. Schirmer's test and TBT, are two useful tests, used to diagnose dry eye syndrome. Intact tear film quantity and quality as proven by normal Schirmer's and TBT tests, are required to maintain healthy epithelial cells of the ocular surface. Due to the impaired secretion of the meibomian glands in patients suffering from rosacea, instability of the tear film and collateral damage of the cornea and conjunctiva may occur.

\section{Group IIA Phospholipase A2 (GIIAPLA2)}

Human tears contain several natural antimicrobial proteins including group IIA phospholipase A2 (GIIAPLA2), lysozyme, lactoferrins, defensins and gamma globulins [30-33]. Altered secretions of these natural antimicrobial peptides may be important in the pathogenesis of rosacea. GIIAPLA2 is a lipolytic enzyme capable of killing a broad spectrum of gram-positive bacteria $[34,35]$. The level of GIIAPLA2 is markedly reduced in patients of rosacea with chronic conjunctivitis predisposing them to bacterial infections [36]. The low values could be explained by increased consumption due to long standing continuous staphylococcal stimulation [37]. 


\section{Lactoferrin}

Secondary to chronic meibomitis and blepharitis Lactoferrin level is also low in patients with ocular rosacea. The low concentration of lactoferrin may play a role in the ocular surface inflammatory components of rosacea [14].

\section{Bacterial Lipases}

Elevated levels of Staphylococcal lipases act upon wax and sterol esters from MG producing toxic free fatty acids, which are another source of inflammation in ocular rosacea [38,39].

\section{Others}

Infestation of eye lashes by Demodex mite and the symbiotic $B$ Oleronius bacteria living inside the mite are strongly correlated with blepharitis and facial rosacea secondary to strong host immune response to proteins produced by $B$. oleronius $[40,41]$.

Culture independentanalysis based on 16s rRNAgene sequences of tear samples from patients with blepharitis showed increase in Staphylococcus organisms and decrease in Propionibacterium. Other ocular pathogens that are considered normal microbial communities such as Streptophyta, Corynbacterium and Enhydrobacter are detected in abundance. It seems that Blepharitis may be induced by mixed microbial flora, pollens, dust and soil particles that are the main source of Streptophyta, Corynbacterium and Enhydrobacter.

Goblet cells are mucous producing, which is central to stabilizing tear film layer. There is a significant decrease in the number of goblet cells in patients presenting with dry eyes [35,42]. Abnormalities of goblet cell number or function could cause eye symptoms in rosacea sufferers.

\section{Clinical Presentation}

The most common symptoms of ocular rosacea are nonspecific and include foreign body, gritty or dry sensation, burning, tearing, or the redness. Frequently the symptoms are out of proportion to the minimal eye findings. Telangiectasia of the lid margins, meibomian gland dysfunction, and blepharitis are the common forms of lid involvement [11]. Lempert reported that $57 \%$ of all patients over age 19 scheduled for chalazion excision had rosacea [12]. Conjunctival involvement in ocular rosacea is usually in the form of a mild bulbar conjunctival hyperemia. Cicatrizing conjunctivitis, conjunctival granuloma, and phlyctenular conjunctivitis are less common conjunctival manifestations [13]. The most common form of corneal involvement is in the form of a superficial punctate keratopathy which usually occurs in the lower $1 / 3$ of the cornea. Peripheral epithelial nodular elevations, recurrent epithelial erosion syndrome, corneal neovascularization with peripheral thinning, and corneal ulcer are the other forms of corneal involvement [13]. Episcleritis, scleritis and vitritis can also be associated with rosacea.

Ocular rosacea commonly affects bilaterally the eyelids, conjunctiva, and the cornea. A dermatologist should inquire about the following symptoms such as dry eyes, burning, itching, ocular irritation and grittiness, redness, photophobia, blurry vision, stabbing pain foreign body sensation occurring during sleep or upon awakening or both (Figure 8). Patients with ocular symptoms are better referred for ophthalmological evaluation. It is of utmost importance to diagnose dry eye syndrome and manage it to avoid corneal vascularization and ulceration that are sight threatening complications.

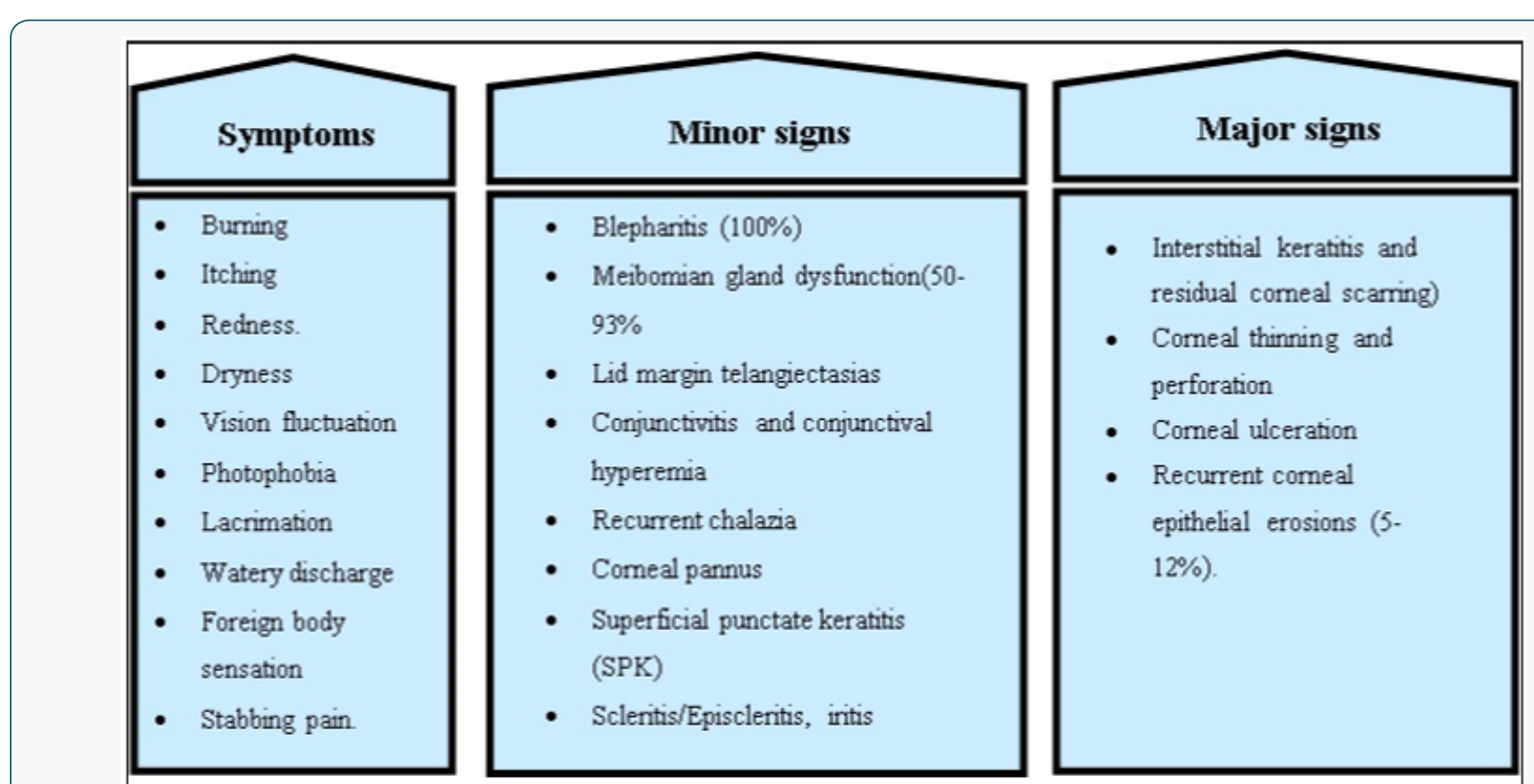

Figure 8: Clinical symptoms and signs of ocular rosacea. 


\section{Eyelids and Meibomian Gland}

Examination of the eyelid is very important looking for crusts, thickening, rounding, erythema, telangiectasia and irregularity of the lid margin (Figures 4-6), and dilatation of conjunctival vessels. Blepharitis presents with erythema and scales or crusts around eyelashes without scarring (Figures 4,9-12) and predisposes to chalaziae (Figures $13 \& 14$ ) that usually present with a short history of recent lid discomfort, followed by acute inflammation (redness, tenderness, and swelling). Rosacea should be considered in patients with recurrent chalaziae since it was almost twice as common as those with only single occurrence of chalazia [43].

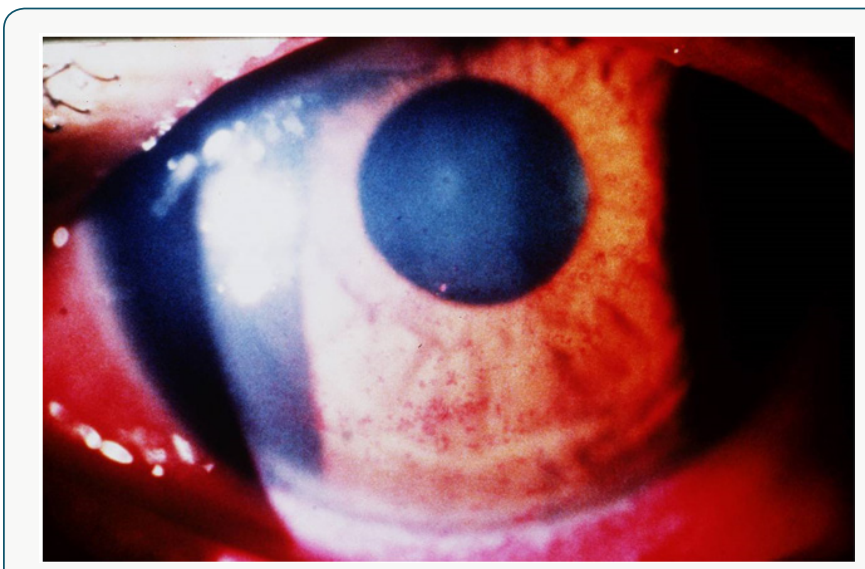

Figure 9: Rose Bengal staining, dry eyes.

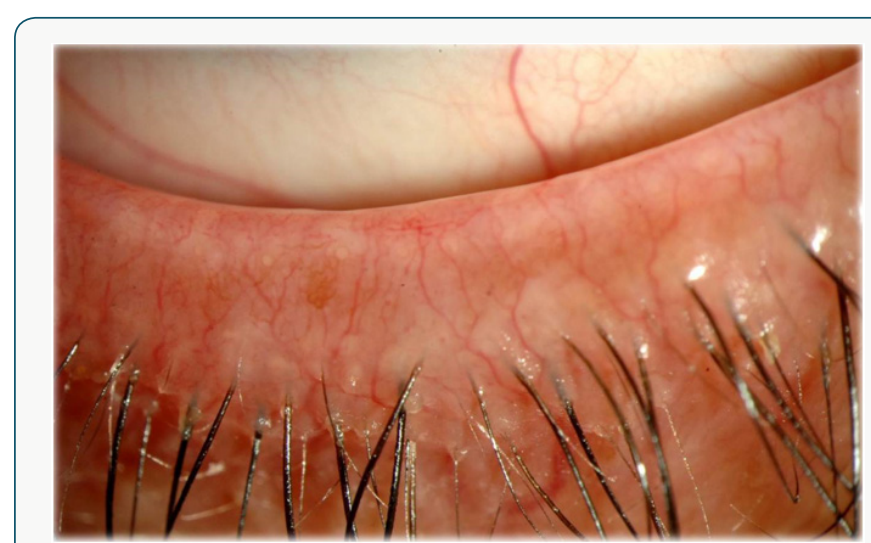

Figure 10: Showing anterior Blepharitis, telengiectasia of lid margin, MGD.

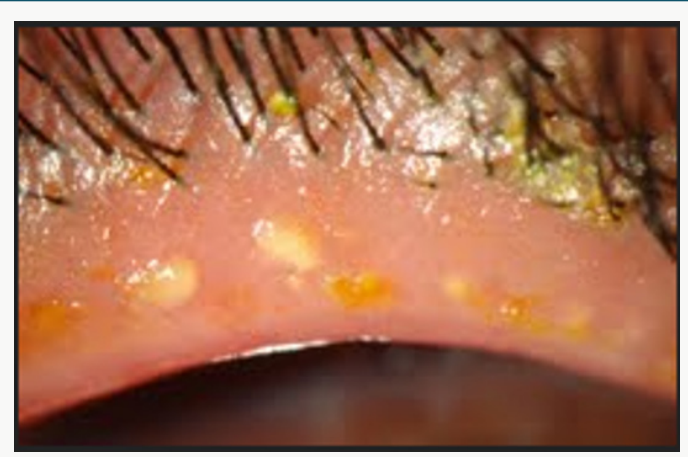

Figure 11: Mixed anterior and posterior blepharatitis. Note the inspisated meibomian gland secretion.

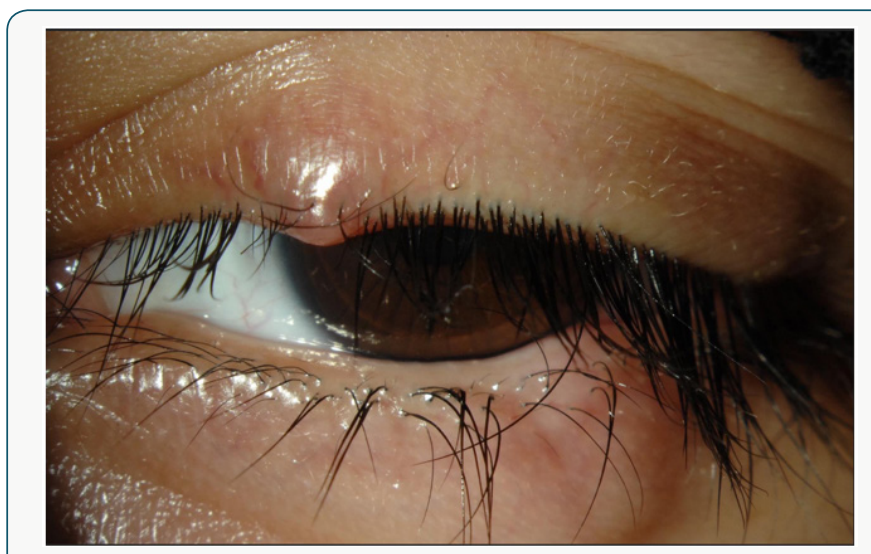

Figure 12: Hordeolum internum of lower eyelid (acute chalazion), externum of upper eyelid (Stye).

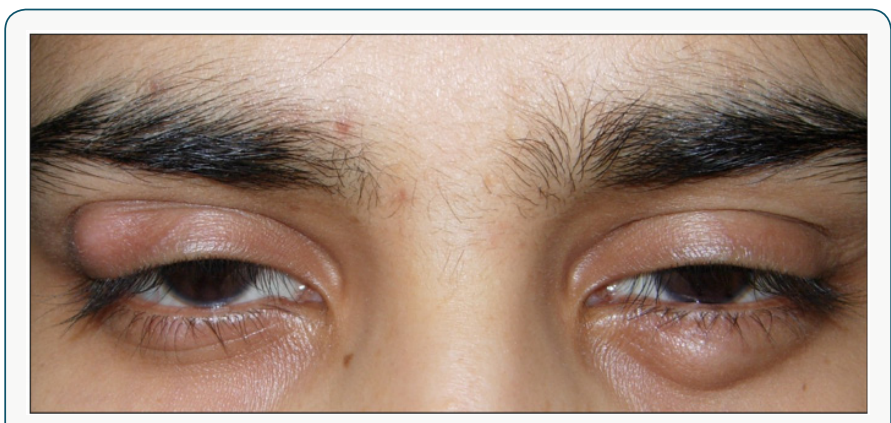

Figure 13: Multiple chalazia.

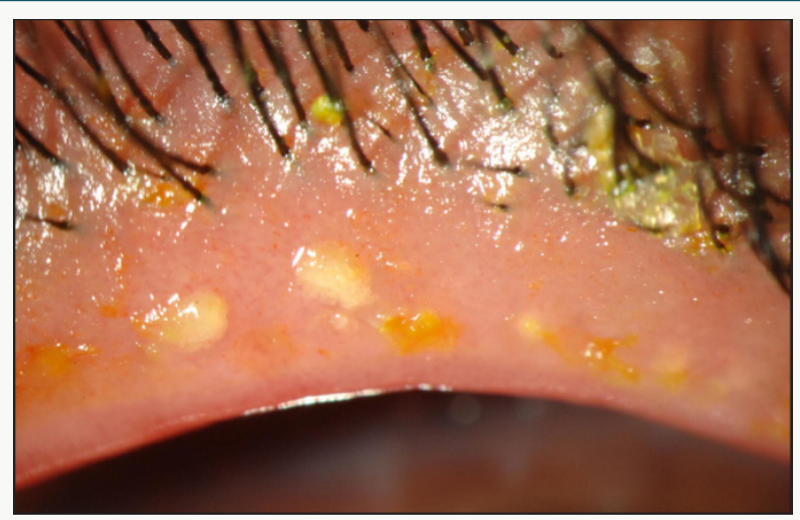

Figure 14: Inspisated meibomian gland secretion.

The symptoms of MGD are non-specific and include burning, red eye, irritation, itching, dryness, and fluctuation of vision. Upon examination, the lid margin is frequently erythematous, irregular, thickened, or rounded with dilatation of palpebral conjunctival vessels and telangictasia around the glandular orifices (Figure 14). The orifices are often plugged with yellowish solid secretions (Figure 6). Since telangiectasia of the lid margin frequently occurs in rosacea [4-49], therefore lid margin examination is very useful in diagnosis of ocular rosacea.

\section{Conjunctiva}

Conjunctivitis presenting with photophobia, profuse lacrimation and together with involvement of interpalpebral 
conjunctival vessels may occur [23]. The discharge of rosacea is watery in nature, but if becomes mucopurulent, infection should be excluded [23]. Chronic diffuse conjunctival hyperemia and granuloma and rarely cicatrization that resemble trachoma can occur [48,50-56]. It is important to remember that the severity of ocular disease is not correlated with cutaneous severity [57].

\section{Cornea}

Recurrent corneal epithelial erosions have been reported to occur in $5 \%$ to $12 \%[13,23]$.

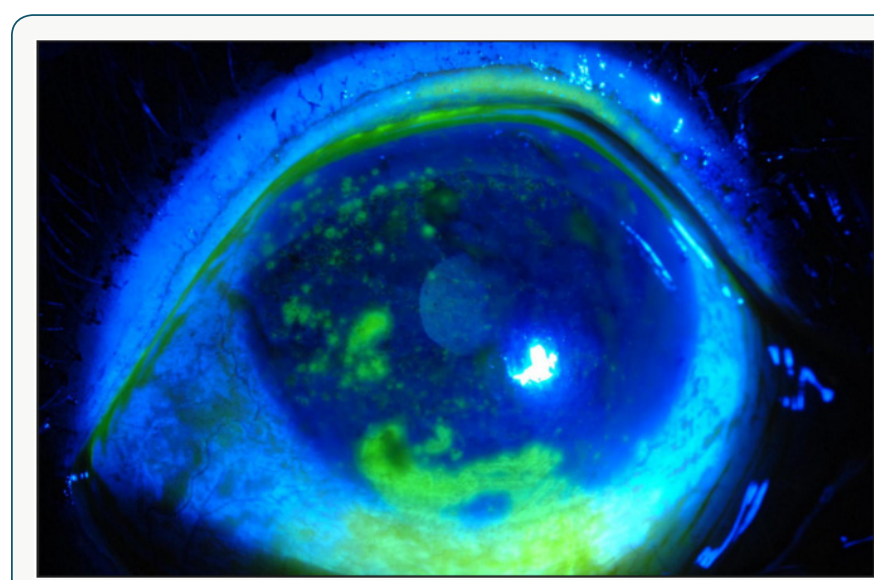

Figure 15: Severe punctate epitheliopathy stained with Fluorescein. Note anterior migration of muco-cutaneous junction on upper eyelid margin.

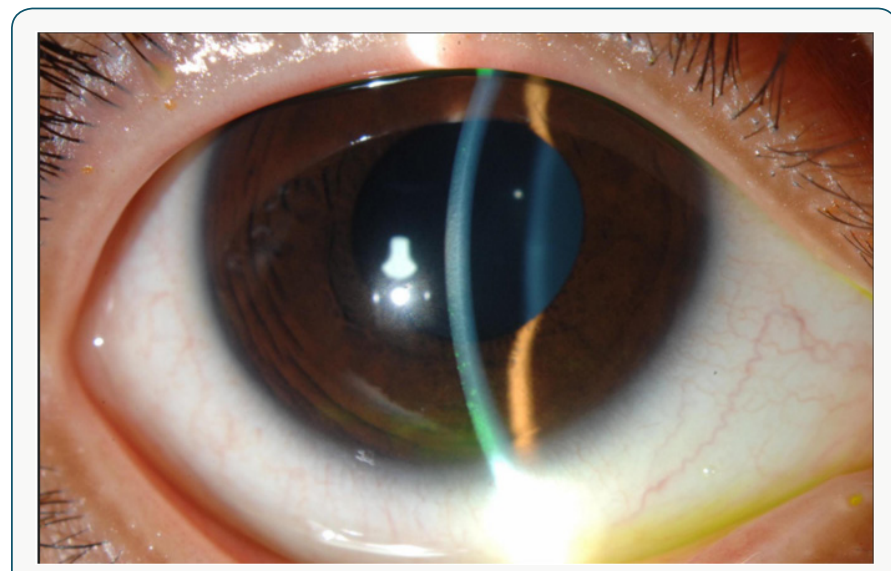

Figure 16: Peripheral corneal infiltrate. Note conjunctival hyperemia and blepharitis.

Symptoms of corneal erosions include stabbing pain and foreign body sensation occurring during sleep or upon awakening or both. It includes the presence of superficial punctate keratitis (Figures 15-18) typically on the lower third of the cornea and always accompanied by neovascularization [28]. Microbiological evaluation should be considered even in cases of sterile keratitis prior to the treatment with topical steroid, so to prevent possible associated fungal keratitis [53]. When vascular invasion of the peripheral cornea occurs, along with subepithelial infiltrates, this type of inflammatory keratitis allows neovascularization to spread circumferentially if left untreated [44-47,54] and blindness may unfortunately occur. Corneal infiltrate (Figure 9), phlyctenules (episcleral nodules) appearing like a small pump or vesicle, edema, peripheral panus, corneal thinning and ulceration or perforation may also occur [49,50,52-54]. Uncommon ocular findings include kerato-conus like features such as high asymmetric astigmatism and inferior corneal thinning, as well as herpes like dendritic corneal lesions [44,54].

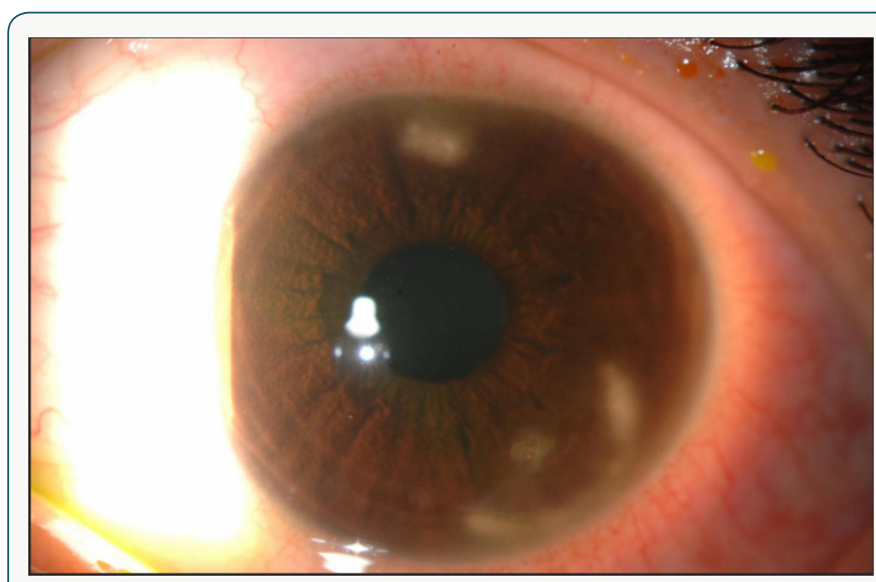

Figure 17: Mild punctate epitheliopathy inferiorly located.

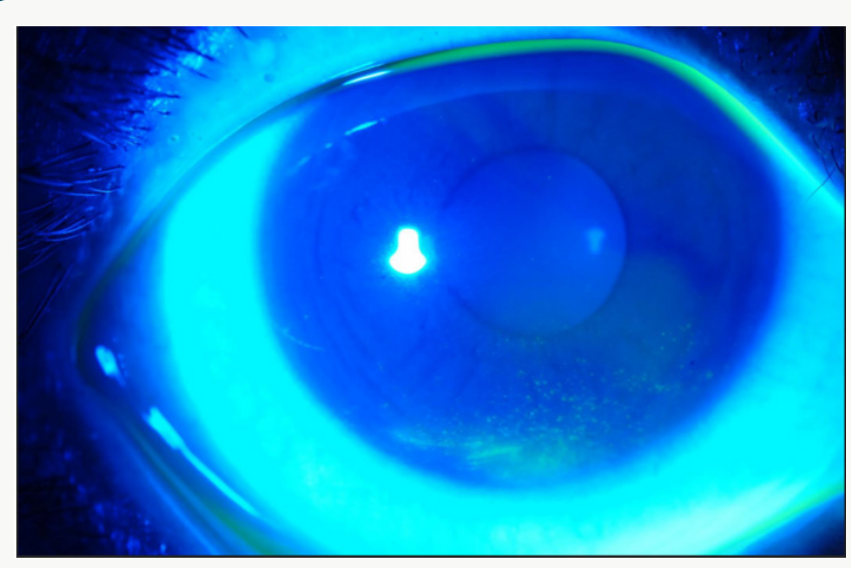

Figure 18: Mild punctate epitheliopathy stained with Fluorescein.

\section{Ocular Rosacea in Children}

Overall, rosacea is rare in children and may be misdiagnosed as viral or bacterial infections [55]. There is no estimate in the literature of ocular rosacea in children, but under diagnosis occurs frequently in this age group [55].

Children usually present with recurrent chalaziae, blepharoconjunctivitis and generalized ocular surface irritation [43] that antedates any cutaneous findings. The case series of pediatric ocular rosacea by Nazir included six patients with age range from 3 to 12 years. In all cases, the patients had chronic irritation of at least 6 months duration with no response to various topical antibiotics and anti-allergy agents [55]. It appears to be commoner in girls than boys, and findings are usually bilateral, although they may be asymmetric. Cutaneous changes are uncommon but when 
found they are predominantly papulopustular with underlying telangiectasia [56].

There are no criteria set for diagnosing ocular rosacea; however, it may be diagnosed after excluding other conditions like herpes simplex keratitis, bacterial infection, or allergic and atopic disease [55]. The presence of lid margin telangiectasia, along with MGD and long history of ocular irritation should point toward a diagnosis of ocular rosacea [55] (Figure 5). Fortunately, treatment of ocular rosacea by oral doxycycline or erythromycin tailored to the age of the patient is helpful but relapses could occur [55].

\section{Diagnosis}

The diagnosis of ocular rosacea should be considered when a patient has one or more of the following symptoms and signs, foreign body sensation, burning or stinging, dry eye, itching, light sensitivity, blurred vision, bloodshot appearance (interpalpebral conjunctival hyperemia) telangiectases of the conjunctiva and lid margin, blepharitis, conjunctivitis, and irregularity of the eyelid margins. MGD presenting as chalaziae or chronic staphylococcal infection are common signs of rosacea-related ocular disease (Figures $10 \& 11$ ). Some patients may have decreased visual acuity caused by corneal complications such as punctate keratitis (Figures 12 \& 13), corneal infiltrates/ulcers, or marginal keratitis. There are no specific test or procedures for diagnosing ocular rosacea. When skin findings are present, routine eye examination is sufficient for establishing the diagnosis.

\section{Slit Lamp Examination}

Slit lamp biomicroscopic examination is performed by ophthalmologists. It is a useful method to inspect the anterior segment of the eye (i.e., lids, lashes, meibomian gland orifices, conjunctiva, cornea, anterior chamber, iris, and lens) both with and without vital dyes (Figure 12).

It is well suited for diagnosing conditions such as eye lid diseases, keratoconjunctivitis and corneal epithelial defect.

By the use of flourescein dye, which does not stain the epithelium, any uptake of the dye means corneal stromal exposure. Flourescein is readily available as a strip, which requires wetting with normal saline or a $2 \%$ sterile single unit dose solution. It absorbs light in blue wavelength and emit green light. The wetted strip or the solution is applied to lower conjunctival surface. It stains broken epithelium and the edges of necrotic tissues of the cornea and conjunctiva. Other dyes such as Rose Bengal or Lissamine green can be used to stain corneal erosions and ulcers (Figure 9).

\section{Supplemental Testing}

No single tear quantity or tear quality test alone is capable of assessing tear film or ocular surface integrity. Diagnosis is more likely to be accurate when it is based on two or more abnormal test results. Tear quantity test include Schirmer tear test. Tear quality and stability tests include Tear film breakup time (BUT), Lactoferrin concentration tests and Lysozyme radial diffusion assay.

\section{Meibography}

The meibomian glands can be examined using in vivo transillumination biomicroscopy with infrared photography "meibography." This is a technique which involves the transillumination of lower lid by everting it over a transilluminator probe. Slit lamp infrared photography shows light transmission by the ducts and hypotransilluminescent spots representing acini. Narrowing or occlusion of the gland orifices, dilatation and distortion of the glands, has been observed with this technique. Chalaziae or cysts appear as enlarged dark spots [57].

\section{Impression Cytology}

Impression cytology (IC) refers to application of a cellulose acetate filter to the ocular surface to remove the superficial and deep layers of the epithelium. These cells are subjected to histological, immunohistochemical or molecular analysis. Histological examination of IC in rosacea showed decreased goblet cells, which results in unstable tears and over expression of inflammatory markers like HLA-DR and ICAM-1 expression by flow cytometry [58].

\section{Histology}

The histology and immunopatholgy of epibulbar conjunctival biopsy showed infiltration mainly with T-helper /inducer (CD4) cells, phagocytic cells and antigen presenting cells. The T-helper cells in rosacea outnumbered the T-suppressor (CD8) in a ratio of $(C D 4 / C D 8=1.6)$ while the ratio in normal individuals is 0.85 . The substance propria contained large numbers of chronic inflammatory cells and occasional granuloma formation. The conjunctival inflammation resembles a type IV hypersensitivity reaction $[59,60]$. Similarly, in the skin, T Helper cells outnumbered $\mathrm{T}$ suppressor cells around extrafolliclar Demodex parts, which support the hypothesis that a cell-mediated immune response plays an important role in the pathogenesis of rosacea [60].

\section{Glycomics Analysis}

Ocular rosacea patients without skin lesions presents a diagnostic challenge. Analysis of tear glycomics (O-linked oligodisaccharides) after tear stimulation by Schirmer paper is considered a diagnostic marker of the disease. Mass spectra analysis of glycomics yields a sensitivity of $100 \%$ and specificity of 95.2\%, which makes the test an objective diagnostic marker [61].

\section{Therapy}

Dermatologists and health providers should always inquire about ocular symptoms, if the patients fail to report them, due to the potential risk of sight threatening ocular complications if not detected and treated early. When patients report any ocular symptoms, referral to ophthalmology is mandatory for baseline evaluation. Situations like dry eyes, if left unmanaged can result in severe corneal assault and resultant vision impairment. The quality of studies evaluating ocular rosacea treatment according to Cochrane database Review has been insufficient. Treatment of 
ocular rosacea can be divided into topical or systemic. The level of evidence will be mentioned with every treatment based on the Table 1: Grading of clinical evidence. criteria adapted from the American Academy of Ophthalmology Practice Guidelines (Table1).

\begin{tabular}{|c|c|}
\hline Level I & $\begin{array}{c}\text { Evidence obtained from at least 1 properly conducted randomized controlled trial OR From studies applying } \\
\text { rigorous statistical approaches. }\end{array}$ \\
\hline Level II & $\begin{array}{c}\text { Evidence obtained from well-designed controlled trial without randomization OR } \\
\text { Well-designed cohort or case control study from many centers OR } \\
\text { Well-designed study applying rigorous statistical analysis. }\end{array}$ \\
\hline Level III & $\begin{array}{c}\text { Evidence obtained from descriptive studies OR } \\
\text { Case reports, Expert committee, Expert opinion, Unpublished proceedings. }\end{array}$ \\
\hline
\end{tabular}

\section{Topical Therapy (Table 2)}

Therapy of ocular rosacea is aimed at control of symptoms and prevention of complications. Most physicians use morning lid hygiene with baby shampoo or using commercially available lid scrubs that are less irritant than baby shampoo to remove meibomian gland clogging, bacterial flora and debris that accumulates overnight [62-64]. Lid scrubs is done by using diluted baby shampoo or the commercially available lid scrubs on a cotton tipped applicator and running it along the lid margin. Romero et

Table 2: Topical ocular rosacea treatments [36,47,52,58,61-78]. al reported in non-randomized uncontrolled prospective study (clinical study level II) that 6 weeks of lid hygiene with hot normal saline compresses and artificial tears (preservative free) improved symptoms in MGD and TBT [64]. Lid scrubs with tea tree oil 50\% every other day have been found to be helpful in the eradication of Demodex mite infestation of the eye lashes that contribute to the occurrence of anterior blepharitis [37,65]. Gao and Kheirrkhah reported that daily tea tree oil shampoo with weekly $50 \%$ tea tree oil massage are useful in eradicating Demodex in 4 weeks $[65,66]$.

\begin{tabular}{|c|c|c|}
\hline Ocular Rosacea Treatments & Dosages Found in the Literature & Symptoms Alleviated \\
\hline Cyclosporine $0,005 \%$ ophthalmic emulsion & $2 x d$ & $\begin{array}{l}\text { Aqueous tear film dysfunction, } \\
\text { Keratitis, Blepharitis }\end{array}$ \\
\hline Polymyxin B/trimethoprim & at bed time and up to $4 x d$ & \multirow{4}{*}{ Blepharitis, MGD, infection } \\
\hline Azithromycin $1 \%$ ophthalmic gel & $2 x d$ for 2 days then at bed time for 2 weeks & \\
\hline Erythromycin $0.5 \%$ ophthalmic & ointment at bed time and up to $6 x d$ & \\
\hline Bacitracin ophthalmic ointment & at bed time and up to every $3-4 \mathrm{~h}$ & \\
\hline Diclofenac $0.1 \%$ ophthalmic solution & $4 \times \mathrm{d}$ & \multirow{5}{*}{ Inflammatory conjunctivitis, Keratitis } \\
\hline Nepafenac $0.1 \%$ ophthalmic sol & $3 x d$ & \\
\hline Bromofenac $0.09 \%$ ophthalmic sol & $2 x d$ & \\
\hline Ketorolac $0.4 \%$ ophthalmic sol & $1-4 \times d$ & \\
\hline $\begin{array}{c}\text { Corticosteroids: } \\
\text { Methylprednisolone } \\
\text { Prednisolone acetate1\% } \\
\text { Loteprendol }\end{array}$ & 4-6xd pulse then taper & \\
\hline $\begin{array}{c}\text { Dexamethasone/Tobramycin suspension/ } \\
\text { ointment Prednisolone / sulfacetamide } \\
\text { Suspension/ointment }\end{array}$ & $\begin{array}{l}\text { at bedtime and up to } 4 x d \\
\text { at bedtime and up to } 4 x d\end{array}$ & $\begin{array}{c}\text { Inflammatory conjunctivitis, Keratitis, } \\
\text { Blepharitis, MGD }\end{array}$ \\
\hline Lid scrubs & $1-2 \times d$ & Blepharitis \\
\hline Hot compresses & $1-6 \times d$ & $\begin{array}{l}\text { Lid hygiene, Blepharitis, MGD, } \\
\text { Chalazia }\end{array}$ \\
\hline Artificial tears, moisturizing gels or ointment & as often as needed & Dry eyes, Keratitis \\
\hline
\end{tabular}

MGD $=$ Meibomialn gland dysfunction.

Warm compresses with a minimum temperature increase of 5 degrees above body temperature for 5-10 minutes and digital massaging of the lid margin. The patient should apply traction on the lateral canthus to immobilize the upper and lower eyelids followed by gentle pressure upward or downward with the fingers

of the opposite hand to helps facilitate the excretion of MG $[63,64]$. Olson et al reported that 5 minutes eyelids hot compresses (40ㅇ) improved MGD in 80\% (clinical studies level II) $[67,68]$.

For the treatment of chalaziae, a self-administered technique called the " 4 fingers times 10 massage" can be beneficial. This 
technique is performed as follows: At the conclusion of a bath or shower, the patient warms his or her hands under hot water. Using 1 drop of baby shampoo (which does not sting eyes), the patient works up lather, places the index finger over the closed lids at the lid margin, and vigorously massages the lid back and forth 10 times. The patient then repeats the procedure with the middle, ring, and little fingers. Acute chalazia are also managed by hot compresses for 5-10 minutes, 4 to 6 times daily. Surgical intervention may be required for persistent chalaziae. There is evidence to support the use of Intralesional corticosteroids for chalazia (clinical studies level II) $[69,70]$.

Punctate keratitis is managed by a variety of topical treatments including preservative free artificial tears, anti-bacterial or antifungal agents for secondary infections after obtaining cultures should be used. Short term use of topical steroids helps decrease inflammatory keratitis, conjunctivitis and lid disease. Cyclosporine $0.05 \%$ ophthalmic emulsion, an inhibitor of the T-cell function, should be considered when treating ocular rosacea induced keratitis [71]. In a study conducted by Schechter (clinical study level I) topical cyclosporine $0.05 \%$ emulsion twice daily for 3 months was found to be more effective than preserved and preservative free artificial tears for the treatment of, rosacea-associated dry eyes, lid and corneal changes [72]. In cases of chronic dry eyes, ophthalmic cyclosporine twice daily for 3 months has been proven to improve tear quantity and quality, MGD, lid margin telangiectasia and corneal staining (clinical studies level I) [72-74].

Topical ophthalmic steroids when used in conjunction with oral doxycycline have been reported to be effective in prevention of recurrent corneal erosions associated with ocular rosacea (clinical study level I) [72]. The potential for increased intraocular pressure, cataract and thinning of the eyelid skin, limit its use for short duration [75]. If opportunistic bacterial or fungal infection occurs, topical steroid should be avoided $[74,75]$.

For significant blepharitis with erythema, adding an antibiotic ointment or combination steroid/antibiotic ointment is common [53]. Topical azithromycin 1\% eye drops for 4 weeks proved to be effective in controlling adult blepharitis with mild burning sensation after instillation and controlling childhood ocular rosacea at $1.5 \%$ concentration 3 days twice daily every 10 days (clinical study level III) [76-78]. Topical cyclosporine $0.05 \%$ ophthalmic emulsion used twice daily has been shown to reduce posterior blepharitis [78]. A single RCT that compared the efficacy of cyclosporine emulsion $0.05 \%$ with artificial tears for conjunctival and corneal ocular rosacea related pathology. The study showed significant improvement of the ocular changes, Schirmer and Tear break up time mean values after 3 months use of cyclosporine emulsion compared with artificial tears.

Topical metronidazole gel $0.75 \%$ to $1 \%$ applied to the lid margin twice daily for 12 weeks combined with lid hygiene may be a safe and effective means of treating rosacea blepharitis (clinical studies level II) [79]. Metronidazole is a broad-spectrum antibiotic with anti-parasitic and anti-inflammatory effects. For sterile corneal ulcers, anti-inflammatory drugs play a role in decreasing ocular inflammation and preventing tissue damage. Diclofenac $0.1 \%$ ophthalmic solution 4 times daily can be used with caution [73].

Local irritant effects of topical ophthalmic NSAIDs include conjunctival hyperaemia, burning, stinging and corneal anaesthesia. A more serious complication includes corneal ulceration and full-thickness corneal melts due to usage of Diclofenac sodium ophthalmic solution. NSAID-induced corneal injury is possibly caused by epithelial hypoxia or the effect on corneal matrix metalloproteinase and direct toxicity of the excipients such as surfactants, solubilizers and preservatives found in topical NSAID ophthalmic preparations. Ophthalmic NSAIDs should not be used with gentamicin which might increase NSAID absorption and toxicity. The concurrent use of NSAIDs with topical corticosteorids in situations such as corneal inflammation has increased the risk for precipitating corneal erosions and melts and such concurrent use should be employed in an appropriate and judicious manner [80].

\section{Systemic Therapy (Table 3)}

Table 3: Oral ocular rosacea treatments [5,9,49,52,60,73-77,80-98].

\begin{tabular}{|c|c|c|}
\hline $\begin{array}{l}\text { Ocular Rosacea } \\
\text { Treatments }\end{array}$ & $\begin{array}{l}\text { Dosage Found in } \\
\text { Literature }\end{array}$ & Symptoms Alleviated \\
\hline Omega 3 fatty acids & $\begin{array}{c}1000-2000 \mathrm{mg} \\
1-2 x d a y\end{array}$ & $\begin{array}{l}\text { Blepharitis, MGD, Tear } \\
\text { film deficiency }\end{array}$ \\
\hline Minocycline & 50-100mg 2xday & \multirow{11}{*}{$\begin{array}{l}\text { Blepharitis, } \\
\text { MGD, Keratitis, } \\
\text { Conjunctivitis }\end{array}$} \\
\hline Doxycycline & $\begin{array}{l}50-100 \mathrm{mg} 2 \mathrm{xd} \\
(20-50 \mathrm{mg}) 1 \times \mathrm{d} \text { as } \\
\text { maintenance }\end{array}$ & \\
\hline Tetracycline & $\begin{array}{l}100-200 \mathrm{mg} 2 \times \text { daily; } \\
500 \mathrm{mg} 2 \mathrm{xd}\end{array}$ & \\
\hline Erythromycin & $200 \mathrm{mg} 2-4 \mathrm{xd}$ & \\
\hline Azithromycin & 250 mg 3xweekly & \\
\hline Clarithromycin & $250-500 \mathrm{mg} 1-2 \mathrm{xd}$ & \\
\hline Isotretinoin & $0.15-2 \mathrm{mg} / \mathrm{kg} / \mathrm{d}$ & \\
\hline H. pylori eradication & $500 \mathrm{mgBID}$ & \\
\hline Metronidazole & $500 \mathrm{mgBID}$ & \\
\hline Clarithromycin & 150mg BID & \\
\hline Ranitidine & 2 weeks course & \\
\hline
\end{tabular}

The choice of topical, systemic or combination therapy usage is guided by the ocular manifestation of the disease. Corneal neovascularization and tear film insufficiency are more responsive to systemic therapy whereas, meibomian gland dysfunction requires combination therapy [53]. Long term intake of 3000$4000 \mathrm{mg}$ of omega 3 fatty acids have been reported to be safe and improve meibomian gland secretion, once symptoms are controlled maintenance dose of $2000 \mathrm{mg} /$ day can be initiated. Beneficial effects of omega 3 require six weeks of consistent intake to be 
recognized [80]. A recently published RCT (clinical studies level I) of the use of omega 3 at a dose of $2000 \mathrm{mg} 3$ times daily for one year in patients with MGD, showed improvement of symptoms and objective clinical measures of the treatment group and to lesser extent on the placebo group [81-84].

Significant ocular disease requires oral antibiotics such as the tetracyclines family, that have been found effective because of their anti-inflammatory properties [85]. It is not clear if the anti-inflammatory properties of tetracyclines are primarily due to inhibition of bacterial lipases, the reduction of the number of bacteria present, inhibition of Phospholipase A2 and matrix metalloproteinase or a combination of these and other unknown factors [85-88]. Studies reported significant improvement in ocular rosacea signs and symptoms including dryness, itching, blurred vision, photosensitivity, erythema, and lid margin telangiectasia with the use of doxycyline (clinical studies level II) $[9,52,89]$. The optimal dose, duration of therapy for ocular rosacea by tetracycline and doxycyline has not been established [88-89]. Dosages and treatment duration is determined by the treating physician and tailored according to patient response. Systemic therapy can be tapered after symptomatic relief. If therapy is tapered too quickly; recurrence is high especially within the first 3 months $[9,50,85-88]$.

Reported doses by some authors for tetracycline $500 \mathrm{mg}$ twice daily for 4-6 weeks, the dose may be subsequently tapered to one tablet every other day according to response [55]. Doxycycline at a dose of 50-100 mg can be given twice daily for one month then 50-100 once daily for 1-2 months before tapering [61]. In a randomized controlled study reported by Yoo (clinical studies level I), low dose doxycycline $20 \mathrm{mg}$ twice daily was found to be effective in controlling eye symptoms and improvement of Schirmer and TBT [90].

Alternative systemic therapy includes erythromycin, azithromycin, metronidazole, and low dose isotretinoin Azithromycin a macrolide antibiotic with high antimicrobial and anti-inflammatory properties has shown promising results in reducing eyelid disease and conjunctival hyperemia, without side effects $[81,82]$. Due to its high conjunctiva and tear fluid concentration that persist for 2 weeks after $1 \mathrm{~g}$ oral dose, pulse dose of $1 \mathrm{~g}$. weekly for 3 weeks was found effective in treating meibomitis (clinical studies level II) [91-93] Clarithromycin, was reported to be as effective as doxycycline, with fewer side effects [83]. Metronidazole has immunosuprssive, anti-inflammatory and antimicrobial effects. Metronidazole can cause stomach upset and alcohol cannot be consumed while taking it $[81,83]$.

Low dose isotretinoin can be initiated in cases resistant to antibiotics and should be used with caution since isotretinoin could cause keratitis and keratoconjunctivitis [5]. Tetracycline is contraindicated in children until 8 years of age as it may cause permanent discoloration of teeth and interfere with tooth enamel development in patients younger than 7 years $[94,95]$. Erythromycin has anti-inflammatory effect through inhibition of synthesis of the bacterial enzymes [94,95], improves the meibomian gland function and TBT and decrease punctate keratopathy [96].

In patients younger than 8 years, oral erythromycin showed success in treating ocular rosacea $[55,61,97,98]$. Nazir et al reported excellent response of ocular rosacea in children with oral erythromycin (clinical studies level III) [55]. For older children, tetracycline and doxycycline may be used in dosages similar to adults [55]. There is a $25 \%$ relapse rate in 1 month and a $66 \%$ rate in 6 months after cessation of tetracycline, therefore prolonged treatment may be required [55]. Patients with $H$. pylori infection, the use of 2 weeks course of metronidazole, clarithromycin, and ranitidine improved the ocular manifestations of rosacea more than cutaneous (clinical studies level III) [99]. A variety of surgical techniques have been used for the repair of corneal defects due to ocular rosacea such as keratoplasty or the use of amniotic membrane transplantation [100-103].

\section{Conclusion}

Unfortunately, ocular rosacea is frequently under diagnosed by dermatologists and undiagnosed by ophthalmologists. Patient fail to complain to dermatologists of minor eye symptom and ophthalmologists do not examine the facial skin to establish the diagnosis. Dermatologists and family physicians should meticulously inquire about ocular symptoms and refer patients to ophthalmology for further management. Symptoms of ocular rosacea include dry eyes, burning, itching, ocular irritation and grittiness, redness, foreign body sensation, photophobia, blurry vision, stabbing pain, foreign body sensation occurring during sleep or upon awakening or both. Telangictasia of the lid margin, MGD, chalazia and blepharitis are the most common forms of lid involvement. Conjunctival involvement in ocular rosacea is usually in the form of a mild bulbar conjunctival hyperemia. Cicatrizing conjunctivitis, conjunctival granuloma and phylctenular conjunctivitis are less common conjunctival manifesttations. The most common form of corneal involvement is in the form of a superficial punctate keratopathy which usually occurs in the lower $1 / 3$ of the cornea. Recurrent epithelial erosion, corneal neovascularization with peripheral thinning, and corneal ulcer are the other forms of corneal involvement. Examination of the eyelid is very important looking for erythema, telangiectasia, crusts, irregularity of the lid margin, thickening rounding, and dilatation of the conjunctival vessels.

The need for properly conducted, well randomized controlled trials is urgent, since there exists no definite conclusion about any of the therapies available nowadays. Strong clinical evidence suggests that topical cyclosporine $0.05 \%$ emulsion is more effective than preserved and preservative free artificial tears for the treatment of, rosacea-associated dry eyes, lid and corneal changes upon any slight suspicion for ocular involvement, patients should be referred for ophthalmological evaluation. Therefore, a clinician's increased awareness of ocular finding in patients with rosacea may aid in 
the earlier diagnosis and treatment, preventing permanent eye impairment.

\section{Acknowledgment}

Many thanks to the colleagues from the department of Ophthalmology, King Abdulaziz University Hospital, King Saud university for providing the clinical pictures. Without their assistance the paper would have been deficient. We express our gratitude namely to: Dr. Yasser AL Faky, MD, FRCS and Dr. Sameer Mansouri MD, FRCS.

\section{References}

1. Doggarts JH (1931) The ocular complications of acne rosacea. Br J Ophthalmol 15: 446-457.

2. Mannis MJ, Macsai MS, Huntley AC (1996) Eye and skin disease. Philadelphia, Pa: Lippincott-Raven Publishers p.19-23.

3. Starr PA (1969) Oculocutaneous aspects of rosacea. Proc R Soc Med 62: 9-11.

4. Browning DJ, Proia AD (1986) Ocular rosacea. Surv Ophthalmol 31: 145158.

5. Kligman AM (1997) Ocular rosacea: Current concepts and therapy. Arch Dermatol 133(1): 89-90.

6. Borrie P (1953) Rosacea with special reference to its ocular manifestations. Br J Ophthalmol 65(12): 458-463.

7. Wilkin JK (1983) Rosacea. Int J Dermatol 22: 393-400.

8. Donshik PC, Hoss DM, Ehlers WH (1992) Inflammatory and papulosquamous disorders of the skin and eye. Dermatol Clin 10(3): 533-547.

9. Quarterman MJ, Johnson DW, Abele DC, Lesher JL, Hull DS, et al. (1997) Ocular rosacea: signs, symptoms, and tear studies before and after treatment with doxycycline. Arch Dermatol 133(1): 49-54.

10. Knox CM, Smolin G (1997) Rosacea. Int Ophthalmol Clin 37(2): 29-40.

11. Gudmundsen KJ, O’Donnell BF, Powell FC (1992) Schirmer testing for dry eyes in patients with rosacea. J Am Acad Dermatol 26(2): 211-214.

12. (1998) Maddin S (Eds.); Rosacea. Skin Ther Lett 3: 3-4.

13. Jenkins MS, Brown SI, Lempert SL, Weinberg RJ (1979) Ocular rosacea. Am J Ophthalmol 88: 618-622.

14. Kiratli H, Irkec M, Orhan M (2000) Tear lactoferrin levels in chronic meibomitis associated with acne rosacea. Eur J Ophthalmol 10(1): 1114.

15. Lemp MA, Mahmood MA, Weiler HH (1984) Association of rosacea and keratoconjunctivitis sicca. Arch Ophthalmol 102(4): 556-557.

16. Yaylali V, Ozyurt C (2002) Comparison of tear function tests and impression cytology with the ocular findings in acne rosacea. Eur J Ophthalmol 12(1): 11-17.

17. Borrie P (1953) Rosacea with special reference to its ocular manifestations. Br J Dermatol 65: 458-463.

18. Mc Culley JP, Dougherty JM (1986) Bacterial aspects of chronic blepharitis. Trans Ophthalmol Soc UK 105(3): 314-318.

19. Lempert SL, Jenkins MS, Brown SI (1979) Chalazia and rosacea. Ophthalmology 97(9): 1652-1653.

20. Lemp MA (1995) Report of the National Eye Institute/Industry Workshop on clinical trials in dry eyes. CLAO J 21(4): 222-232.

21. McCauley JP, Sciallis GF (1977) Meibomian keratoconjunctivitis. Am J Ophthalmol 84(6): 788-793.
22. Burton JL, Pye RJ, Meyrick G (1975) The sebum excretion rate in rosacea. BrJ Dermatol Res 92(5): 541-543.

23. Apek EA, Merchard A, Pinar V, Foster CS (1997) Ocular rosacea: patient characteristics and follow-up. Ophthalmology 104(11): 1863-1867.

24. Browning DJ, Proia A (1986) Ocular rosacea. Surv Ophthalmol 31(3): 145-158.

25. Driver PJ, Lemp MA (1996) Meibomian gland dysfunction. Surv Ophthalmol 40: 343-367.

26. Barton K, Monroy D, Nava A, Pflugfelder SC (1997) Inflammatory cytokines in tears of patients with ocular rosacea. Ophthalmology 104(11): 1868-1874.

27. Woessner JF (1991) Matrix metalloproteinases and their inhibitors in connective tissue remodeling. FASEB J 5(8): 2145-2154.

28. Afonso AA, Sorbin L, Monoroy Dc, Selzer M, Lokeshwar B, et al. (1999) Tear fluid gelatinase B activity correlates with IL- $1 \alpha$ concentration and fluorescein clearance in ocular rosacea. Invest Ophthalmol Vis Sci 40(11): 2506-2512.

29. Iovieno A, Lambiase A, Micera A, Stampachiacchiere B, Sgrulletta $\mathrm{R}$, et al. (2009) In vivo characterization of doxycycline effects on tear metalloproteinases in patients with chronic blepharitis. Eur J Ophthalmol 19(5): 708-716.

30. Gudmundsen KJ, O Donnell BF, Powell FC (1992) Schirmer testing for dry eyes in patients with rosacea. J Am Acad Dermatol 26: 211-214.

31. Machado LM, Castro RS, Fontes B M (2009) Staining patterns in dry eye syndrome: Rose bengal versus lissamine green. Cornea 28 (7): 732-734.

32. Mondino BJ (1991) Host defense against bacterial and fungal disease. Tasman W, Jaeger EA, JB Lippincott (eds.); Philadelphia p. 1-19.

33. Aho VV, Nevalainen TJ, Saari KM (2002) Group IIA phospholipase A2 content of tears in patients with keratoconjunctivitis sicca. Graefes Arch Clin Exp Ophthalmol 240(7): 521-523.

34. Haynes RJ, Tighe P, Harminder SD (1999) Antimicrobial defensin peptides of the human ocular surface. Br J Ophthalmol 83(6): 737-741.

35. Qu XD, Lehrer RJ (1998) Secretory phospholipase A2 is the principal bactericide for staphylococci and other gram-positive bacteria in human tears. Infect Immun 66(6): 2791-2797.

36. Moreau JM, Girgis DO, Hume EBH, Dajcs JJ, Austin MS, et al. (2001) Phospholipase A2 in rabbit tears: a host defense against Staphylococcus aureus. Invest Ophthalmol Vis Sci 42(10): 2347-2354.

37. Kari O, Aho VV, Peltonen S, Saari JM, Kari M, et al. (2005) Group IIA phospholipase A2 concentration of tears in patients with ocular rosacea. Acta Ophthalmol Scand 83(4): 483-486.

38. Dougherty JM, McCulley JP (1986) Bacterial lipases and chronic blepharitis. Invest Ophthalmol Vis Sci 27(4): 468-491.

39. Milikan LE (2004) Rosacea as an inflammatory disorder: A unifying theory? Cutis 73(1): 5-8.

40. Jianjing LI, Nimah O’Reilly, Sheba H, Katz R, Vadrevu KR, et al. (2010) Correlation between ocular Demodex infestation and serum Bacillus proteins in patients with facial rosacea. Ophthalmology 117(5): 870877.

41. Lee SH, DH OH, JY Jung, JC Kim, CO Jeon (2012) Comparative ocular microbial communities in humans with and without Blepharitis. Invest Ophthalmol Vis Sci 53(9): 5585-5593.

42. Pisella PJ, Brignole F, Debbasch C, Lozato PA, Creuzot-Garcher C, et al. (2000) Flow cytometric analysis of conjunctival epithelium in ocular rosacea and keratoconjunctivitis sicca. Ophthalmology 107(10): 18411849.

43. Lempert SL, Jenkins MS, Brown SI (1979) Chalazia and rosacea. Arch Ophthalmol 97(9):1652-1653. 
44. Lee WB, Darlington JK, Mannis MJ (2005) Dendritic keratopathy in ocular rosacea. Cornea 24(5): 632-633.

45. Donaldson KE, Karp CL, Dunbar MT (2007) Evaluation and treatment of children with ocular rosacea. Cornea 26(1): 42-46.

46. Dennis L (2003) Identifying and treating ocular rosacea. Physician Assistant 27(7): 33-35.

47. Stone DU, Chodosh J (2004) Oral tetracyclines for ocular rocasea: An evidence-based review of the literature. Cornea 23(1): 106-109.

48. Odom R, Dahl M, Dover J, Draelos Z, Drake L, et al. (2009) Standard management options for rosacea, Part 2: Options according to subtype. Cutis 84(2): 97-104.

49. Quarterman M, Johnson D, Abele D, Lesher JL, Hull DS, et al. (1997) Ocular rosacea: Signs, symptoms, and tear studies before and after treatment with doxycycline. Arch Dermatol 133(1): 49-54.

50. Albert DL, Brownstein S, Jackson WB (1992) Conjunctival granulomas in rosacea. Am J Ophthalmol 113(1): 108-110.

51. Ravage ZB, Beck AP, Macsai MS, Ching SS (2004) Ocular rosacea can mimic trachoma: A case of cicatrizing conjunctivitis. Cornea 23(6): 630631.

52. Keshtcar Jafari A, Akhyani M, Ehsani AH (2009) Correlation of the severity of cutaneous rosacea with ocular rosacea. Indian J Dermatol Venereol Leprol 75: 405-406.

53. Jain V, Shome D, Sajnani M, Natarajan S (2010) Fungal keratitis associated with ocular rosacea. Int Ophthalmol 30(3): 239-244.

54. Dursun D, Piniella AM, Pflugfelder SC (2001) Pseudokeratoconus caused by rosacea. Cornea 20(6): 668-669.

55. Nazir SA Scott M, Siatkowski RM, Chodosh J, Siatkowski RL (2004) Ocular rosacea in childhood. Am J Ophthalmol 137: 138-144.

56. Chamaillard M, Mortemousque B, Boralevi F (2008) Cutaneous and ocular signs of childhood rosacea. Arch Dermatol 144(2): 167-171.

57. Tapie R (1977) Etude biomicroscopique des glandes de Meibomius. Ann Ocul 210: 637-648.

58. Koçak Altintas AG, Kocak-Midillioğlu I, Gül U, Bilezikci B, Isiksaçan O, et al. (2003) Impression cytology and ocular characteristics in ocular rosacea. Eur J Ophthalmol13(4): 351-359.

59. Hoang Xuan T, Rodriguez A, Zaltas MM, Rice BA, Foster CS (1990) Ocular rosacea: A histologic and immunopathologic study. Ophthalmology 97(11): 1468-1475.

60. Rufli T, Büchner SA (1984) T-cell subsets in acne rosacea lesions and the possible role of Demodex folliculorum. Dermatologica 169(1): 1-5.

61. An HJ, Ninonuevo M, Aguilan J, Liu H, Lebrilla CB, et al. (2005) Glycomics analyses of tear fluid for the diagnostic detection of ocular rosacea. J Proteome Res 4(6): 1981-1987.

62. G Geerling, J Tauber, C Baudouin, E Goto, Y Matsumoto, et al. (2011) The international workshop on meibomian gland dysfunction: Report of subcommittee on management and treatment of meibomian gland dysfunction. IOVS 52: 2050-2064.

63. Barclay L (2009) Treatment of acne rosacea reviewed. Am Fam Physician 80: 461-468.

64. Romero JM, Biser SA, Perry HD (2004) Conservative treatment of meibomian gland dysfunction. Eye Contact Lens 30(1):14-19.

65. Pitts J, Lievens C (2009) Put the squeeze in meibomian gland disease. Rev Optom 146(9): 82-87.

66. Gao YY, DI Pasculae MA, Elizondo A, Tseng SC (2007) Clinical treatment of ocular democidosis by lid scrubs with tea tree oil. Cornea 26(2): 136143.
67. Kherikhah A, Casas V, Li W, Raju VK, Tseng SC (2007) Corneal manifestations of ocular demodex infestation. Am J OPhthalmol 143(5): 743-749.

68. Solomon J, Case C, Greiner J (2007) Warm compress induced visual degradation and Fischer-Schweitzer polygonal reflex. Optom Vis Sci 84(7): 580-587.

69. Olson MC, Korb DR, Greiner JV (2003) Increase in tear film lipid layer thickness following treatment with warm compresses in patients with meibomian gland dysfunction. Eye Contact Lens 29(2): 96-99.

70. Epstein GA, Putterman AM (1988) Combined excision and drainage with intra lesional corticosteroid injection in the treatment of chronic chalazia. Arch Ophthalmol 106: 514-516.

71. Palva J, Pohjanpelto PE (1983) Intralesional corticosteroid injection for the treatment of chalazia. Acta Ophthalmol (Copenh) 61: 933-937.

72. Donnenfeld E, Pflugfelder SC (2009) Topical ophthalmic cyclosporine: Pharmacology and clinical uses. Surv Ophthalmol 54(3): 321-338.

73. Schechter BA, Katz RS, Friedman LS (2009) Efficacy of topical cyclosporine for the treatment of ocular rosacea. Adv Ther 26(6): 651659.

74. Dursun D, Kim MC, Solomon A, Pflugfelder SC (2001) Treatment of recalcitrant recurrent corneal erosions with inhibitors of matrix metalloproteinase-9, doxycycline, and corticosteroids. Am J Ophthalmol 132: 8-13.

75. Baratz KH, Hattenhaur MG (2000) Indiscriminate use of corticosteroidscontaining eye drops. Mayo Clin Proc 75: 539.

76. Perry HD, Donnenfeld ED (2004) Topical $0.05 \%$ cyclosporine in the treatment of dry eye. Expert Opin Pharmacother 5(10): 2099-2107.

77. Mantelli F, Di Zazzo A, Sacchetti M, Dianzani C, Lambiase A, et al. (2013) Topical azithromycin as a novel treatment for ocular rosacea. Ocul Immunol Inflamm 21(5): 371-377.

78. Doan S, Gabison E, Chiambaretta F, Touati M, Cochereau I (2013) Efficacy of azithromycin $1.5 \%$ eye drops in childhood ocular rosacea with phlyctenular blepharo-keratoconjunctivitis. J Ophthalmic Inflamm Infect 3(1): 38.

79. Barnhorst DA, Foster JA, Chern KC, Meisler DM (1996) The efficacy of topical metronidazole in the treatment of ocular rosacea. Ophthalmology 103(11): 1880-1883.

80. Gaynes BI, Fiscella R (2002) Topical nonsteroidal anti-inflammatory drugs for ophthalmic use: A safety review. Drug Saf 25(4): 233-250.

81. Sutphin JE, Dana MR, Florakis GJ (2006) Basic and Clinical Science Course, Section 8: External Disease and Cornea. Am Acad Ophthalmol 84-86.

82. Jackson WB (2009) Management of dysfunctional tear syndrome: A Canadian consensus. Can J Ophthalmol 44(4): 385-394.

83. Creuzot C, Passemard M, Viau S, PO Lafontaine, C Joffre, et al. (2006) Improvement of dry eye symptoms with polyunsaturated fatty acids. J Fr Ophthalmol 29(8): 868-873.

84. Rashid S, Jin Y, Ecoiffier T, Barabino S, Schaumberg DA, et al. (2008) Topical omega- 3 and omega- 6 fatty acids for treatment of dry eye. Arch Ophthalmol 126(2): 219-225.

85. Alexander LJ (2009) The essentials of essential fatty acids. Rev Optom 146(9): 62-63.

86. Macsai MS (2008) The role of omega-3 dietary supplementation in blepharitis and meibomian gland dysfunction (an AOS thesis). Trans Am Ophthalmol Soc 106: 336-356.

87. Dougherty JM, Mc Culley JP, Silvany RE, Meyer W (1991) The role of tetracyclines in chronic blepharitis inhibition of lipase production in staphylococci. Invest Ophthalmol Vis Sci 32(11): 2970-2975. 
88. Ta CN, Shine WE, Mc Culley JP, Pandya A, Trattler W, et al. (2003) Effects of minocycline on the ocular flora in patients with acne rosacea or seborrheic blepharitis. Cornea 22(6): 545-548.

89. Sadowaki T, Steinmeyer J (2001) Effects of tetracycline on the production of matrix metalloproteinases and plasminogen activators as well as of their natural inhibitors, tissue inhibitor of metalloproteinases- 1 and plasminogen activator inhibitor -1. Inflamm Res 50: 175-182.

90. Stone DU, Chodosh J (2004) Oral tetracycline for ocular rosacea: an evidence-based review of the literature. Cornea Jan 23(1): 106-109.

91. Culp B, Scheinfeld N (2009) Rosacea: A review. Pharm Ther Jan 34(1): 38-45.

92. Yoo SE, Lee DC, Chang MH (2005) The effect of low dose doxycycline therapy in chronic meibomian gland dysfunction. Korean J Ophthalmol 19: $258-263$

93. Bakar O, Dermicary Z, Toker E, Cakir S (2009) Ocular signs, symptoms, and tear function tests of papulopustular rosacea patients receiving azithromycin. J Eur Acad Dermatol venerol 23(5): 544-549.

94. Randleman JB, Loft E, Song CD (2009) Ocular rosacea. eMedicine from WebMD.

95. JB Greene, RE Fintelman, TP Margolis (2014) Oral azithromycin for treatment of meibomitis. JAMA Ophthalmol 132(1): 121-122.
96. Howard R, Tsuchiya A (1998) Adult skin disease in the pediatric patient. Pedia Dermatol 16(3): 593-608.

97. Meisler D, Raizman M, Traboulsi E (2000) Oral erythromycin treatment for childhood blepharok. Oral erythromycin treatment for childhood blepharokeratitis eratitis. JAAPOS 4: 379-380.

98. Erzurum S, Feder R, Greenwald M (1993) Acne rosacea with keratitis in childhood. Arch Ophthalmol 111(2): 228-230.

99.Zaidman G, Brown S (1981) Oraly administered tetracycline for phlyctenular keratoconjunctivitis. Am J Ophthalmol 92(2): 178-182.

100. Oltz M, Check J (2011) Rosacea and its ocular manifestations. Optom 82(2): 92-103.

101. Daković Z, Vesić S, Vuković J, Milenković S, Janković-Terzić K (2007) Ocular rosacea and treatment of symptomatic Helicobacter pylori infection: a case series. Acta Dermatovenerol Alp Panonica Adriat 16(2): 83-86.

102. Gracner B, Pahor D, Gracner T (2006) Repair of an extensive corneoscleral perforation in a case of ocular rosacea with a keratoplasty. Klin Monbl Augenheilkd 223(10): 841-843.

103. Jain AK, Sukhija J (2007) Amniotic membrane transplantation in ocular rosacea. Ann Ophthalmol 39: 71-73.

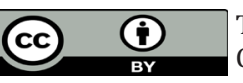

This work is licensed under Creative Commons Attribution 4.0 License

To Submit Your Article Click Here:

Submit Article
DOI: 10.32474/TRSD.2018.01.000107

\section{Theranostics of Respiratory \& Skin Diseases}

\section{TRSD}

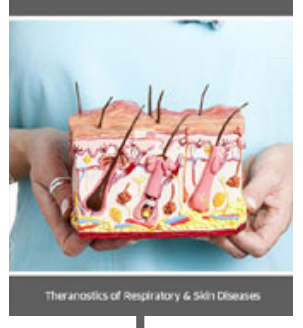

\section{Assets of Publishing with us}

- Global archiving of articles

- Immediate, unrestricted online access

- Rigorous Peer Review Process

- Authors Retain Copyrights

- Unique DOI for all articles 